\title{
Effect of various dialysis modalities on intradialytic hemodynamics, tissue injury and patient discomfort in chronic dialysis patients: design of a randomized cross-over study (HOLLANT)
}

Paul A. Rootjes, Menso J. Nubé, Camiel L. M. de Roij van Zuijdewijn, Gertrude Wijngaarden and Muriel P. C. Grooteman * (D)

\begin{abstract}
Background: From a recent meta-analysis it appeared that online post-dilution hemodiafiltration (HDF), especially with a high convection volume (HV-HDF), is associated with superior overall and cardiovascular survival, if compared to standard hemodialysis (HD). The mechanism(s) behind this effect, however, is (are) still unclear. In this respect, a lower incidence of intradialytic hypotension (IDH), and hence less tissue injury, may play a role. To address these items, the HOLLANT study was designed.

Methods: HOLLANT is a Dutch multicentre randomized controlled cross-over trial. In total, 40 prevalent dialysis patients will be included and, after a run-in phase, exposed to standard HD, HD with cooled dialysate, low-volume HDF and high-volume HDF (Dialog $\mathrm{iQ}^{\circledR}$ machine) in a randomized fashion. The primary endpoint is an intradialytic nadir in systolic blood pressure (SBP) of $<90$ and $<100 \mathrm{mmHg}$ for patients with predialysis SBP $<159$ and $\geq 160$ $\mathrm{mmHg}$, respectively. The main secondary outcomes are 1) intradialytic left ventricle (LV) chamber quantification and deformation, 2) intradialytic hemodynamic profile of SBP, diastolic blood pressure (DBP), mean arterial pressure (MAP) and pulse pressure (PP), 3) organ and tissue damage, such as the release of specific cellular components, and 4) patient reported symptoms and thermal perceptions during each modality.

Discussion: The current trial is primarily designed to test the hypothesis that a lower incidence of intradialytic hypotension contributes to the superior survival of (HV)-HDF. A secondary objective of this investigation is the question whether changes in the intradialytic blood pressure profile correlate with organ dysfunction and tissue damage, and/or patient discomfort.
\end{abstract}

Trial registration: Registered Report Identifier: NCT03249532 (ClinicalTrials.gov). Date of registration: 2017/08/15.

Keywords: Hemodialysis, Hemodiafiltration, Intradialytic blood pressure, Intradialytic tissue injury, Intradialytic patient tolerance, Multicentre randomized controlled cross-over trial

\footnotetext{
* Correspondence: mpc.grooteman@amsterdamumc.nl

Department of Nephrology and Amsterdam Cardiovascular Sciences (ACS),

Amsterdam UMC, VU University of Amsterdam, Amsterdam, The Netherlands
}

(c) The Author(s). 2021 Open Access This article is licensed under a Creative Commons Attribution 4.0 International License, which permits use, sharing, adaptation, distribution and reproduction in any medium or format, as long as you give appropriate credit to the original author(s) and the source, provide a link to the Creative Commons licence, and indicate if changes were made. The images or other third party material in this article are included in the article's Creative Commons licence, unless indicated otherwise in a credit line to the material. If material is not included in the article's Creative Commons licence and your intended use is not permitted by statutory regulation or exceeds the permitted use, you will need to obtain permission directly from the copyright holder. To view a copy of this licence, visit http://creativecommons.org/licenses/by/4.0/ The Creative Commons Public Domain Dedication waiver (http://creativecommons.org/publicdomain/zero/1.0/) applies to the data made available in this article, unless otherwise stated in a credit line to the data. 


\section{Background}

Despite the use of high permeable dialyzers, which combine diffusive with convective transport, the clinical outcome of hemodialysis (HD) patients remains poor. In online post-dilution hemodiafiltration (HDF), diffusion is by and large similar to HD, while the amount of convective transport is considerable higher. Recently, four randomized controlled trials (RCT) have been published which compared HD with HDF [1-4]. Although the results of the individual studies were inconclusive, a recent meta-analysis on individual participant data (IPD) showed a superior outcome for patients treated with HDF (allcause mortality HR 0.86 [95\% CI: 0.75 ; 0.99]). The largest mortality reduction was obtained in patients receiving the highest convection volume (high-volume HDF [HV-HDF] $>23 \mathrm{~L} / 1.73 \mathrm{~m}^{2} /$ session: all-cause mortality $\mathrm{HR} 0.78$ [95\% CI: 0.62; 0.98], if compared to HD) [5].

Nonetheless, it is still unclear why HV-HDF is associated with an improved survival [6]. On theoretical grounds, both the enhanced removal of middle molecular weight uremic retention products and a superior bioincompatibility (BI) profile [7], including less inflammation $[8,9]$ and less dialysis-induced hypoxia [10, 11], may play an important role. Moreover, since treatment with HDF has been associated with a lower incidence of intradialytic hypotension (IDH) than standard HD [12-15], in which an altered sodium removal during HDF may play a role [16], a lesser amount of dialysis-induced tissue damage may also contribute to the beneficial effect of HDF on survival.

Since IDH is a frequently occurring side-effect of HD treatment and microcirculatory dysfunction is a prominent feature of patients with advanced chronic kidney disease (CKD) [17, 18], every single dialysis session may further deteriorate the already affected structure and function of vital organs, such as the brain, gut and heart [19]. After all, HD-associated cardiomyopathy may result not only from the various inflammatory and metabolic derangements of pre-dialysis CKD [20], but also from HD-induced perfusion deficits [21-27], which is considered a model of repetitive organ ischemia-reperfusion injury. In this respect it is interesting to note that an absolute intradialytic nadir of SBP $<90$ and $<100 \mathrm{mmHg}$ for patients with a predialysis SBP $<159$ and $\geq 160$ $\mathrm{mmHg}$, respectively, appeared most strongly associated with mortality in a large study, comparing the relation between various definitions of IDH and outcome [28]. Considering the gut, HD-induced hypoperfusion may cause disruption of the intestinal barrier and permit the translocation of gut-derived endotoxins, bacterial DNA and/or intact bacteria into the blood. Circulating bacterial fragments may contribute to systemic inflammation, cardiovascular disease, and reduced survival in these patients [29-34].
As intradialytic blood pressure measurements were not the primary endpoint in any of the above-mentioned studies in HDF patients [12-15], it is still unclear if, and if so, why this modality is associated with less IDH than standard HD (S-HD). Since IDH can be alleviated by $\mathrm{HD}$ treatment with cooled dialysate (C-HD) and (HV-) HDF may induce cooling of the extracorporeal circuit and subsequent cooling of the patient, thermal factors may play an important role in this respect [12-15, 3544 ] and are even considered to be exclusively responsible for the superior outcome of HDF treatment [45]. Yet, despite the physical benefits of a reduction in IDH and related symptoms, patients may suffer from shivering and cold (sensations). Interestingly, from a large recent $\mathrm{RCT}$ it appeared that intradialytic patient tolerance was significantly better during HDF, if compared to treatment with S-HD [3]. As of yet, however, it is unknown which intermittent extracorporeal renal replacement therapy (S-HD, C-HD, LV-HDF or HV-HDF) has the most favorable intradialytic patient tolerance profile. Altogether, current data suggests that (HV)-HDF is the preferred treatment to circumvent dialysis-induced IDH, and hence, to alleviate the repetitive microcirculatory dysfunction and subsequent tissue damage of dialysis treatment. So far, however, comparative data between $S$ $\mathrm{HD}, \mathrm{C}-\mathrm{HD}, \mathrm{LV}-\mathrm{HDF}$ and HV-HDF are lacking.

Therefore, the protocol for the current investigation with the original title "Effect of high-volume Online hemodiafiLtration on intradiaLytic hemodynamic (iN)sTability and cardiac function in chronic hemodialysis patients" (HOLLANT) was designed. In this randomized cross-over clinical study, not only intradialytic hemodynamics will be investigated, but also changes in cardiac performance and signs of myocardial injury. In addition, besides markers of inflammation and oxidative stress, intradialytic tissue damage, as indicated by various cell surface markers and the transfer of microbial DNA (mDNA) from the gut to the blood, will be investigated. Hence, finally, since cool dialysate may induce cold (sensations) and shivering [37], patient tolerance and thermal perception will be compared between the four modalities.

\section{Objectives}

The primary objective of the HOLLANT study is to evaluate whether intradialytic hemodynamic stability is better preserved during HV-HDF, by comparing the frequency of intradialytic hypotensive episodes between $\mathrm{S}$ HD, C-HD, LV-HDF and HV-HDF. The main secondary objectives include intradialytic signs of tissue damage as measured by Speckle Tracking Echocardiography (STE), a diversity of laboratory parameters, and patient reported outcome measures (PROMs), such as tolerance and cold (sensations). 


\section{Methods}

\section{Study design}

The HOLLANT study is an open, cross-over, multicenter, intervention RCT in chronic intermittent dialysis patients who will be exposed to four different dialysis modalities: 1) S-HD: HD with a dialysate temperature of $36.5^{\circ} \mathrm{C}$. 2) C-HD: HD with a dialysate temperature $35.5^{\circ} \mathrm{C}$. 3) LV-HDF: HDF with a convection volume of $15 \mathrm{~L} / 1.73 \mathrm{~m}^{2} /$ session and a dialysate temperature of $36.5^{\circ} \mathrm{C}$. 4) HV-HDF: HDF with a convection volume of $\geq 23 \mathrm{~L} / 1.73 \mathrm{~m}^{2} /$ session and a dialysate temperature of $36.5^{\circ} \mathrm{C}$.

After enrollment, participants will be randomized centrally to the four dialysis modalities by using computer randomization software [46]. Randomization occurs in blocks. Enrolled patients will be treated with their usual dialysis modality (either HD or HDF) during the first 2 weeks of the study. Patients who cannot achieve or tolerate a blood flow rate $\geq 350 \mathrm{~mL} / \mathrm{min}$ during this run-in phase will be excluded before the actual start of the study. Treatment times will be fixed at $4 \mathrm{~h}$ per session during the entire conduct of the study. Thereafter, patients start the study-phase and will be treated with $\mathrm{S}$ HD, C-HD, LV-HDF or HV-HDF in a random order. Each dialysis modality will last 2 weeks. The total study duration is 2 (run-in phase) +8 (study phase) $=10$ weeks per patient. An overview of the study is shown in Fig. 1.

\section{Study population}

We plan to include 40 patients. For reasoning (see "Sample size considerations" below), patients will be recruited from three dialysis facilities: a commercial dialysis clinic (Niercentrum aan de Amstel, Amstelveen, The Netherlands), a large community based clinical hospital (St. Antonius Hospital, Nieuwegein, The Netherlands) and a university hospital (Amsterdam UMC, location VU University Medical Center, Amsterdam, The Netherlands). The in- and exclusion criteria are depicted in Table 1. Severe incompliance to the dialysis procedure and accompanying prescriptions is defined as non-adherence to the dialysis prescription.
Table 1 Inclusion and exclusion criteria

Inclusion criteria
- Patients treated with HD or HDF $3 \times$ per week during at least $4 \mathrm{~h}$ for
at least 2 months.
- Ability to understand study procedures.
- Willingness to provide informed consent.
- Dialysis single-pool Kt/N for urea (spKt/Nurea) $\geq 1.2^{\text {a }}$
- Achievement of a blood flow of $\geq 350 \mathrm{ml} / \mathrm{min}$ and/or convection
volume of $\geq 23$ Liter per treatment during the run-in phase.
- Dialysis access recirculation $<10 \%{ }^{\text {a }}$.
Exclusion criteria
- Age < 18 years.
- Life expectancy < 3 months.
- Participation in another clinical intervention trial.
- Severe incompliance to the dialysis procedure and accompanying
prescriptions.

${ }^{a}$ Based on the most recent (before start of the study) measurements from daily practice, in accordance with the applicable national and international guidelines $[47,48]$

\section{Dialysis prescription and equipment Dialysis modalities}

HDF will be performed in the post-dilution mode with a target convection volume (substitution volume + net ultrafiltration [UF] volume) of $15 \mathrm{~L}$ (LV-HDF) or $25 \mathrm{~L}$ ( $\geq 23 \mathrm{~L}, \mathrm{HV}-\mathrm{HDF}$ ). Extracorporeal blood flow rate will be targeted at $350-400 \mathrm{ml} / \mathrm{min}$ and filtration fraction (blood flow rate / convection flow rate) at 25-30\%, which have been proven to be feasible [49]. Substitution fluid is prepared from the dialysis fluid by one additional step of UF with a dialysis fluid filter (Diacap ${ }^{\circledR}$ Ultra, B. Braun Avitum AG, Melsungen, Germany), before it is infused into the blood after the dialyzer. The electrolyte composition of the substitution fluid is identical to the electrolyte composition of the dialysate.

For a given patient, treatment settings will be kept similar in all treatment modalities, e.g. UF profile, start of treatment with either empty or filled lines, blood flow rate, session length and type of anticoagulant. Any clinically necessary change will be documented.

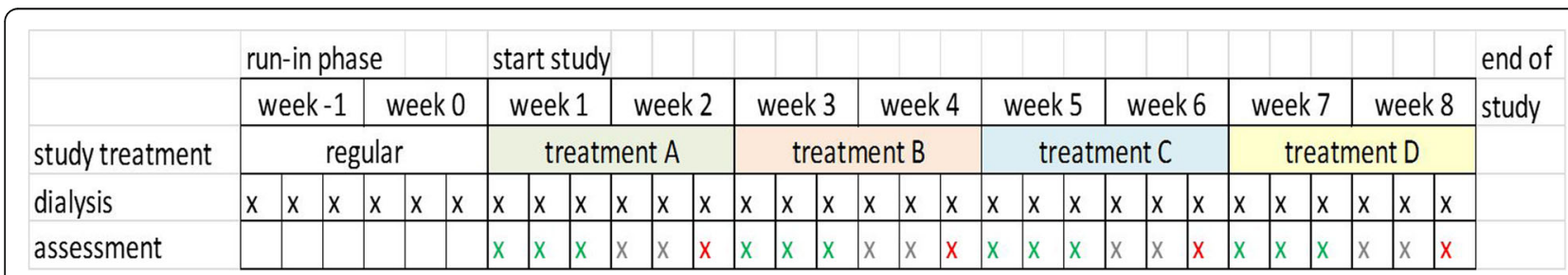

Fig. 1 Overview of study scheme. The run-in phase during week - 1 and week 0 (total duration of 2 weeks) is followed by the four different dialysis treatment modalities (S-HD, C-HD, LV-HDF, HV-HDF) in a randomized order (total duration of 8 weeks). $x=$ Non-invasive advanced hemodynamic monitoring (Clearsight) during the first or second treatment of the last week and measurement of blood pressure every 15 min; $\mathrm{x}=$ assessment of STE, blood sampling and measurement of blood pressure every 15 min; $\mathrm{x}=$ measurement of blood pressure every 30 min 


\section{Dialyzers}

Both HD and HDF will be performed with high-flux dialyzers: Xevonta 23 dialyzers (membrane material: Amembris, i.e. polysulfon-based membrane with polyvinylpyrrolidone; UF coefficient: $124 \mathrm{ml} / \mathrm{min} / \mathrm{mmHg}$; surface area $2.3 \mathrm{~m}^{2}$; sterilization by gamma radiation; capillary internal diameter $195 \mu \mathrm{m}$; B. Braun Avitum AG, Melsungen, Germany). In exceptional cases, the attending nephrologist can decide to treat the patient with a Xevonta $^{\circ} 18$ dialyzer (membrane material: Amembris, UF coefficient $99 \mathrm{ml} / \mathrm{min} / \mathrm{mmHg}$; surface area $1.8 \mathrm{~m}^{2}$; sterilization by gamma radiation; capillary internal diameter $195 \mu \mathrm{m}$; B. Braun, Avitum AG, Melsungen, Germany), or comparable.

\section{Dialysis machines}

All dialysis treatments will be performed on the Dialog $\mathrm{iQ}^{\circ}$ dialysis machine equipped with Adimea ${ }^{\circ}$, automatic blood pressure monitor (ABPM), Hematocrit (HCT) sensor with integrated oxygen saturation (spO2) monitoring device, mantled with the captive tubing system DiaStream $^{\circ}$ iQ (all B. Braun Avitum AG, Melsungen, Germany).

\section{Dialysis fluids}

All treatments will be performed with ultrapure (UP) dialysis fluids $(<0.1 \mathrm{CFU}$ [colony forming units] $/ \mathrm{ml},<0.03$ $\mathrm{EU}$ [endotoxin units] $/ \mathrm{ml}$ ). Dialysate flow rate will be 500 $\mathrm{mL} / \mathrm{min}$ during S-HD and C-HD, and $600 \mathrm{ml} / \mathrm{min}$ in $\mathrm{LV}$ and HV-HDF (as the substitution fluid is derived from the dialysate flow, the dialysis machine automatically increases the dialysate flow during online HDF). The electrolyte composition of the dialysis fluid is: $\mathrm{Na} 138-140 \mathrm{mmol} / \mathrm{L}$; K 2.0-3.0 mmol/L; HCO3 30-35 mmol/L; Ca 1.25-1.75 $\mathrm{mmol} / \mathrm{L} ; \mathrm{Mg} 0.5 \mathrm{mmol} / \mathrm{L} ; \mathrm{Cl} 108-109.5 \mathrm{mmol} / \mathrm{L}$; glucose $5.6 \mathrm{mmol} / \mathrm{L}$; acetate $3 \mathrm{mmol} / \mathrm{L}$ and will not be changed for each individual patient during the conduct of the study.

\section{Patient care}

Routine patient care is performed according to current national [47] and international [48] quality of care guidelines, including the measurement of single-pool Kt/V for urea (spKt/Vurea) and access recirculation. As in daily clinical practice, dry-weight is assessed weekly by the attending nephrologist by evaluating clinical symptoms, edema and blood pressure before, during and after dialysis. All patients will be administered their usual dose of low molecular weight heparin (LMWH) anticoagulation (i.e. nadroparin or dalteparin). No sodium profiling will be applied and the conductivity of the dialysis fluid will be recorded continuously by the Dialog $\mathrm{iQ}$ dialysis machine during the conduct of the study. When a symptomatic IDH occurs during treatment with a dialysate temperature ( $\mathrm{Td}$ ) of $36.5^{\circ} \mathrm{C}$ and there is no reaction to fluid administration, $\mathrm{Td}$ will be lowered by $0.5-1.0^{\circ} \mathrm{C}$ according to standard protocol and noted on patients' individual record list.

\section{Data collection}

Table 2 provides an overview of the data that will be collected during the study.

\section{Baseline data registration}

At baseline, all relevant information will be documented: i.e. demographical data, information on cardiovascular disease (CVD), cause of renal failure, time on dialysis, co-morbidity, medical history and medication. A history of CVD is defined as a confirmative answer on any of the questions regarding a previous acute myocardial infarction, coronary artery bypass graft, percutaneous transluminal coronary angioplasty, angina pectoris, stroke, transient ischemic attack, intermittent claudication, amputation, percutaneous transluminal angioplasty, peripheral bypass surgery, and renal percutaneous transluminal angioplasty.

\section{Baseline laboratory assessments}

Data will be used from the last routine assessment as indicated by the national guideline [47]: $\mathrm{Hb}, \mathrm{Ht}$, phosphate, calcium, parathyroid hormone (PTH); spKt/ $\mathrm{V}$ urea (monthly). Residual kidney function will be expressed as the estimated GFR (eGFR), calculated by the mean of 24-h urinary creatinine and urea clearances and adjusted for body surface area $(\mathrm{mL} / \mathrm{min} / 1.73 \mathrm{~m} 2)$. The plasma concentrations used for this calculation are the mean of the values before and after dialysis. eGFR is considered zero in patients with a urinary production $<100 \mathrm{~mL} /$ day.

\section{Dialysis-related recordings}

Before dialysis, the bodyweight and the interdialytic weight gain (IDWG) of the patients will be noted. During dialysis, hemodynamics will be recorded according to the protocol (see below) as well as all other treatment related variables, including UF volume, UF rate and online monitoring of estimated $\mathrm{Kt} / \mathrm{V}$ from UV-absorbance measurements in spent dialysate via Adimea [50]. Furthermore, data on the anticoagulation type and dose, vascular access (central venous catheter [CVC], graft or AV fistula, including documentation of distance between arterial needle and anastomosis in the 2 latter, vascular access flow (if fistula or graft), needle size and type, blood pump speed, dialysis machine and dialyzer. In case of HDF treatment, the achieved convection volume will be noted at the end of each procedure. Convection volumes will be calculated as the sum of the intradialytic weight loss and the substitution volume in L/session. 
Table 2 Overview of collected variables

\author{
Hemodynamic parameters \\ Markers of cardiac damage \\ Markers of endothelial damage \\ Markers of gut ischemia \\ Markers of inflammation \\ Special biomarkers \\ Patient tolerance \\ Others
}

Intradialytic SBP, DBP, MAP, PP, HR, IDH events, Clearsight measurements

CK-MB, EVs, intradialytic speckle tracking echocardiography

sV-ICAM-1, EVs

mDNA, sCD14

hs-CRP, IL-6R, EVs

FGF23 C-term, EVs

DSI, VAS-TP

pO2 from the arterial line, $\mathrm{SaO} 2$, body temperature
Finally, at the end of each dialysis procedure the patients achieved dry weight will be recorded.

\section{Patient tolerance}

Since simple questions on intradialytic symptoms appear to predict patient outcomes better than complicated questionnaires [51-53], a modified version of the Dialysis Symptom Index (DSI) will be handed out after each treatment period (Table 3). Thermal perception will be assessed by the Visual Analogue Scale - Thermal Perception (VAS-TP) [54, 55], before $\mathrm{HD}(\mathrm{F})$ and after 1 and 3 h (Fig. 2). Upon a continuous line, patients can indicate their actual thermal perception.

\section{Hemodynamic monitoring}

Diastolic (DBP) and systolic (SBP) blood pressure, pulse pressure (SBP minus $\mathrm{DBP})$, mean arterial pressure (MAP: $[(\mathrm{SBP}+2 * \mathrm{DBP}) / 3])$, heart rate $(\mathrm{HR})$ and intradialytic hypotensive episodes (IDH, see Primary endpoint) will be recorded before, after and during each dialysis treatment every $30 \mathrm{~min}$ (during the first week of every treatment modality) and every $15 \mathrm{~min}$ (during the second week). Measurements will be performed with a manometric cuff in different sizes, which is connected to the dialysis machine (automatic blood pressure measurement cuff, B. Braun Avitum AG, Melsungen, Germany).

\section{Non-invasive advanced hemodynamic monitoring}

During the first or second dialysis of the last week of every treatment modality, every 20 seconds MAP, stroke volume (SV), heart rate, total peripheral resistance and cardiac output $(\mathrm{CO})$ will be obtained using the Clearsight monitor (BMEYE/Edwards Lifesciences, Amsterdam, The Netherlands), which is a non-invasive arterial pressure measuring device. This monitor turns finger arterial pressure with a fast-pneumatic system to

Table 3 Modified Dialysis Symptom Index (DSI)

\begin{tabular}{|c|c|c|c|c|c|}
\hline During the past week: did you experience this symptom? & Not at all & A little bit & Some-what & Quite a bit & Very much \\
\hline 1. Dizziness or lightheadedness & 0 & 1 & 2 & 3 & 4 \\
\hline 2. Nausea & 0 & 1 & 2 & 3 & 4 \\
\hline 3. Vomiting & 0 & 1 & 2 & 3 & 4 \\
\hline 4. Headache & 0 & 1 & 2 & 3 & 4 \\
\hline 5. Muscle cramps & 0 & 1 & 2 & 3 & 4 \\
\hline 6. Swelling of the legs & 0 & 1 & 2 & 3 & 4 \\
\hline 7. Shortness of breath & 0 & 1 & 2 & 3 & 4 \\
\hline 8. Chest pain & 0 & 1 & 2 & 3 & 4 \\
\hline 9. Itching & 0 & 1 & 2 & 3 & 4 \\
\hline 10. Feeling cold & 0 & 1 & 2 & 3 & 4 \\
\hline 11. Shivering & 0 & 1 & 2 & 3 & 4 \\
\hline 12. Feeling tired or lack of energy & 0 & 1 & 2 & 3 & 4 \\
\hline $\begin{array}{l}\text { 13. Recovery time after dialysis: } \\
0=\text { none } \\
1=\text { after } 1 \mathrm{~h} \\
2=\text { after half a day } \\
3=\text { the next day } \\
4=\text { the day of the next dialysis }\end{array}$ & 0 & 1 & 2 & 3 & 4 \\
\hline \multicolumn{6}{|c|}{ Are there any other symptoms not mentioned on this questionnaire that you have experienced during the past week? } \\
\hline
\end{tabular}




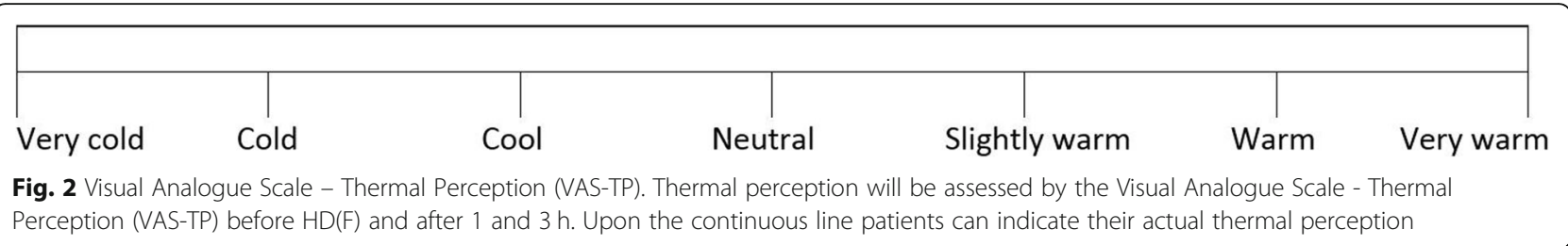

account, as well as photoplethysmography to detect changes in finger arterial diameter during inflations [56]. A volume clamp method is used whereby rapid variations in the cuff pressure allow maintenance of a constant arterial diameter, with an automatic algorithm (Physiocal). The pressure within the cuff is therefore reflective of finger arterial pressure [56]. The Clearsight finger cuff will be attached to the mid-phalanx of the third digit of the hand at the contralateral side of the dialysis shunt. The heart reference system will be placed on the middle of the left side of the thorax. The measured hand and the manometric arm cuff are placed at the mid-thorax to account for hydrostatic pressure differences.

\section{Body temperature}

Body temperature will be assessed before and after each dialysis session by a tympanic thermometer (Genius 2 Tympanic Thermometer, Covidien, Mansfield, USA).

\section{D speckle tracking echocardiography}

Speckle Tracking Echocardiography (STE) will be performed before, after 1 and after $3 \mathrm{~h}$ of treatment during the last dialysis of each modality. Two-dimensional left ventricular (LV) measurements of wall thickness and cavity diameters, 2D biplane Simpson measurement of volumes and ejection fraction are measured using a commercial scanner (Affiniti 70C, Philips Healthcare, The Netherlands) with a fully sampled matrix array (S51) transducer. These measurements are indexed for body surface area (BSA). For the assessment of global longitudinal deformation (GLS) as well as distribution of regional longitudinal strain, 2DSTE is performed from an apical position. Diastolic LV function is measured by 2D LAVI (left atrial volume index), transmitral E/A ratio and deceleration time, e' wave velocity, E/e' ratio and SPAP (systolic pulmonary artery pressure). Estimated right ventricular function will be done by TAPSE (tricuspid annular plane systolic excursion), s' wave velocity and RV (right ventricular) regional and global strain. The data will be recorded electronically and assessed off-line by a trained research physician in Xcelera Cardiology Information Management Version 4.1 (Philips Healthcare, The Netherlands).

\section{Blood sampling}

Blood sampling will be performed in the last session of each dialysis modality, after the long interdialytic interval (see Fig. 1). Blood samples will be drawn from the arterial line of the extracorporeal circuit (ECC) before treatment (but after administration of LMWH) and after $4 \mathrm{~h}$ of treatment (see Table 2). After processing, all blood samples will be stored at $-80^{\circ} \mathrm{C}$ until assessment in the central laboratory of the hospital of the Amsterdam University Medical Centers.

\section{Markers of inflammation, cardiac- and endothelial damage and FGF23}

Soluble CD14 (sCD14), interleukin-6 receptor (IL-6R), high sensitive C-reactive protein (hs-CRP), creatine kinase myocardial band (CK-MB), soluble vascular intercellular cell adhesion molecule 1 (sv-ICAM-1), and fibroblast growth factor $23 \mathrm{C}$-terminal (FGF23 C-term) will be assessed in EDTA or heparin plasma samples after being placed on ice and centrifuged within $30 \mathrm{~min}$, at $1800 \mathrm{~g}$ for $10 \mathrm{~min}$.

\section{Relative blood volume and oxygenation}

Hematocrit measurements, reflecting relative blood volume (RBV), and spO2 will be assessed continuously in the ECC by the HCT sensor and with the integrated spO2-monitoring device located on the Dialog $\mathrm{iQ}^{\circ}$ dialysis machine (B. Braun Avitum AG, Melsungen Germany). RBV- and spO2 values will be read out from the trend-files, which are retrieved by service technicians. In addition, blood samples for $\mathrm{pO} 2, \mathrm{pH}$, bicarbonate and base excess analysis will be drawn from the arterial line before and after treatment (at the moment of activation and before de-activation of the oxygen saturation monitoring device on the Dialog $\mathrm{iQ}^{\circ}$ ), and assessed directly with a point-of-care device (Epoc blood analysis, Epocal Inc., Ottawa, ON, Canada).

\section{Bacterial DNA}

Microbial DNA (mDNA) will be assessed in EDTA blood with 16S-23S interspace (IS) pro after DNA isolation. In short, IS-pro is a eubacterial PCR-based technique for detection of most bacterial species within a sample, and is based on length and sequence polymorphisms of the bacterial 16S-23S ribosomal interspace 
regions. IS-pro has been optimized to detect bacterial loads as low as $1 \mathrm{CFU}$ per $5 \mathrm{ml}$ blood $[57,58]$.

\section{Extracellular vesicles}

Citrate blood samples will be centrifuged for $15 \mathrm{~min}$ at $2500 \mathrm{~g}, 20^{\circ} \mathrm{C}$ to remove red blood cells. Subsequently, the EV-containing supernatant is isolated and centrifuged again $\left(15 \mathrm{~min}\right.$ at $\left.2500 \mathrm{~g}, 20^{\circ} \mathrm{C}\right)$. The $\mathrm{EV}$-containing supernatant will be frozen and stored at $-80^{\circ} \mathrm{C}$ until further use. Before assessment, samples will be thawed at $37^{\circ} \mathrm{C}$. Subsequently, direct measurement of the EVs in plasma will take place, as extensively described by van der Pol et al. [59].

\section{Endpoints}

\section{Primary endpoint}

The primary endpoint of this study is an absolute intradialytic nadir in SBP of $<90$ and $<100 \mathrm{mmHg}$ for patients with a predialysis $\mathrm{SBP}<159$ and $\geq 160$, respectively.

\section{Secondary endpoints}

Secondary endpoints include: 1) intradialytic LV chamber quantification and deformation (longitudinal function with speckle tracking) and LV diastolic function; 2) the intradialytic hemodynamic profile of SBP, DBP, MAP and PP; 3) organ and tissue damage, such as the release of specific cellular components; and 4) patientreported symptoms and thermal perceptions during each modality.

\section{Statistical methods}

Descriptive data will be represented as mean \pm standard deviation (SD), median (interquartile range) or number (percentage), when appropriate. The between-treatment number of IDH episodes (based on an intradialytic nadir in SBP as described above) will be analyzed using regression analysis with a Poisson distribution. The mean inter-treatment variability of continuous variables will be calculated using generalized linear mixed effects models with a random intercept, random slope or both, based on the lowest Aikaike's Information Criterion. A twosided $p$-value $\leq 0.05$ is considered statistically significant. Statistical evaluations will be performed using IBM SPSS Statistics version 26.0 (Chicago, IL, USA) or RStudio version 1.1.456.

\section{Sample size considerations}

We plan to include 40 patients. Loss to follow-up (due to an event) is expected to be about $20 \%$. The number of patients with complete follow-up will be sufficient to detect a $40 \%$ lower risk (relative risk of $0.60, \alpha=0.05$, $\beta=0.80$ ) in the occurrence of the primary endpoint. The power calculation applied was designed for cross-over studies [60].

\section{Data management}

Clinical data will be extracted from the hospital's electronic information systems and dialysis machines. Data will be collected on electronic case record forms (CRF) using web-based Castor EDC [61]. Data will be entered in the data file by an experienced research nurse or research physician. Beforehand, ranges will be defined in the electronic file for all data values to ensure their validity and integrity. Data entry will be checked for $5 \%$ of randomly selected CRFs. Patient data will be coded. Analyzing and publication of the results of this study will be performed anonymously.

\section{Potential consequences of the COVID-19 pandemic}

Given the current COVID-19 pandemic and the fact that this study is carried out in a vulnerable population, it is conceivable that the practical implementation of this study will encounter some serious obstacles. As such, interventions requiring direct patient contact and performed solely in the interest of the study, such as cardiac ultrasounds, may be undesirable in times of alarming virus spread.

\section{Discussion}

The HOLLANT study is principally designed to evaluate prospectively whether intradialytic hypotension, as defined under the primary endpoint, is less frequently observed during HV-HDF than during the three other modalities (S-HD, C-HD and LV-HDF). Second, the study aims to assess whether a more favourable intradialytic hemodynamic profile, as measured by various hemodynamic parameters including MAP and DBP, is associated with a lower degree of tissue injury and organ dysfunction, and a better patient tolerance. After all, it is conceivable that a lower blood pressure and/or diminished perfusion is accompanied by tissue injury, organ dysfunction and subjective discomfort, since pre-existing microcirculatory dysfunction is already present in the majority of patients with advanced CKD [17]. In the present study, all these aspects are addressed and, depending on the outcome, analysed for potential interrelationships.

As for the heart, functional changes as observed by STE, will be correlated with intradialytic hemodynamics and with biochemical signs of myocardial damage, such as an increase in the blood levels of CK-MB and release of EVs from cardiomyocytes. Considering the gut, hypoperfusion of the intestinal microcirculation may promote enterocyte injury, loss of the gut-blood-barrier function and increased permeability, thus permitting the intradialytic transfer of mDNA into the circulation. Any increase during dialysis will be correlated with both blood pressure alterations and changes in the inflammatory state, as measured by sCD14 and IL-6R. Tissue injury of 
various origin, including circulating blood cell elements, the endothelium and cardiomyocytes will be assessed by measuring alterations in the blood levels of EVs. The latter parameters will be correlated with intradialytic hemodynamics as well, and the aforementioned signs of tissue injury, including a rise in CK-MB and mDNA in the blood. Finally, all topics will be related to changes in tympanic body temperature, oxygen and inflammatory status, patient reported temperature sensations and treatment tolerance.

If HV-HDF appears indeed to be associated with a better intradialytic hemodynamic profile and less tissue damage, this will enhance our understanding why HDF is associated with a superior patient outcome and allow the nephrological community to improve this treatment modality even further. If not, the outcome of this study will anyhow teach us if, and to what extent intradialytic hemodynamic instability is associated with tissue injury and patient discomfort, and thus help the medical staff to optimize dialysis treatment in individual cases.

The largest strength of this study is its randomized cross-over design, which prevents that inter-individual differences, such as co-morbidity and prescribed medication, influence the results. An important limitation may be the duration of each dialysis modality, which may be too short to answer all questions. Yet, to minimize patients' discomfort the underlying protocol was designed in its current form. Since this study is primarily designed to investigate the intradialytic hemodynamics and its consequences on organ and tissue damage between the four most practiced extracorporeal dialysis techniques (S-HD, C-HD, LV-HDF and HV-HDF), potential differences in thermal and sodium balance are not addressed. Another important issue of any study with a cross-over design is the duration of the wash-out period that will most likely prevent carry-over effects of the previous modality. For this study, a wash-out period of 1 week (the first week of every treatment modality) was arbitrarily chosen, since relevant information on this topic is absent.

\section{Trial status}

The recruitment and inclusion of patients started at 2908-2018. Currently, 25 (62.5\%) of the intended 40 patients have been included in the study.

\footnotetext{
Abbreviations

BP: Blood pressure; BI: Bio-incompatibility; BSA: Body surface area; CVC: Central venous catheter; CRF: Case record forms; CK-MB: Creatine kinase myocardial band; CFU: Colony forming units; C-HD: Cooled hemodialysis; Cl: Confidence interval; CVD: Cardiovascular disease; CO: Cardiac output; DSI: Dialysis Symptom Index; DBP: Diastolic blood pressure; eGFR: Estimated glomerular filtration rate; EV: Extracellular vesicles; EDTA: Ethylenediaminetetraacetic acid; EU: Endotoxin units; ECC: Extracorporeal circuit; FGF23 C-term: Fibroblast growth factor 23 Cterminal; GLS: Global longitudinal deformation; HR: Heart rate; HD: Hemodialysis; HDF: Hemodiafiltration; HCT: Hematocrit; Hb: Hemoglobin;
}

HV-HDF: High-volume hemodiafiltration; hs-CRP: High sensitive C-reactive protein; HOLLANT: Effect of various dialysis modalities on intradialytic hemodynamics and cardiac function in chronic dialysis patients; IDH: Intradialytic hypotension; IS: Interspace region; IDWG: Interdialytic weight gain; IL-6R: Interleukin-6 receptor; IS-pro: 16S-23S interspace; KDOQI: Kidney Disease Outcomes Quality Initiative; LV: Left ventricular; LVHDF: Low-volume hemodiafiltration; LAVI: Left atrial volume index; LMWH: Low-molecular weight heparin; MAP: Mean arterial pressure; MMW: Middle molecular weight; mDNA: Microbial DNA; PTH: Parathyroid hormone; PP: Pulse pressure; PBS: Phosphate-buffered saline;

PCR: Polymerase chain reaction; PROMs: Patient reported outcome measures; RV: Right ventricular; RBV: Relative blood volume; RCT: Randomized controlled trial; SPAP: Systolic pulmonary artery pressure; SD: Standard deviation; SBP: Systolic blood pressure; S-HD: Standard hemodialysis; SCD14: Soluble CD14; SV-ICAM-1: Soluble vascular intercellular cell adhesion molecule 1; spO2: Oxygen saturation; SV: Stroke volume; S5-1: Sampled matrix array transducer; STE: Speckle tracking echocardiography; spKt/ Vurea: Dialysis single-pool Kt/N for urea; TAPSE: Tricuspid annular plane systolic excursion; Td: Dialysate temperature; TRPS: Tunable resistive pulse sensing; UF: Ultrafiltration; UP: Ultrapure; VAS-TP: Visual Analogue Scale Thermal Perception

\section{Acknowledgements}

The following persons contributed to the design of the HOLLANT study protocol:

Frans J. van Ittersum ${ }^{1}$, Andries E. Budding ${ }^{2}$, Hetty J. Bontkes ${ }^{3}$, Otto Kamp ${ }^{4}$ and Rienk Nieuwland ${ }^{5}$.

(1) Department of Nephrology and Amsterdam Cardiovascular Sciences (ACS), Amsterdam UMC, University of Amsterdam, Amsterdam, The Netherlands.

(2) Department of Medical Microbiology and Infection Control, Amsterdam UMC, VU University Amsterdam, Amsterdam, The Netherlands.

(3) Department of Clinical Chemistry, Medical Immunology Laboratory, Amsterdam Infection \& Immunity, Amsterdam UMC, VU University, Amsterdam, The Netherlands.

(4) Department of Cardiology, Amsterdam UMC, VU University Amsterdam, Amsterdam, The Netherlands.

(5) Laboratory of Experimental Clinical Chemistry, Department of Clinical Chemistry, and Vesicle Observation Center, Amsterdam UMC, Amsterdam, The Netherlands.

\section{Authors' contributions}

MPCG and MJN designed and edited the study protocol. CLMRZ wrote the statistical part of the protocol. PAR wrote the manuscript. MPCG, MJN,

CLMRZ and GW were responsible for the critical revision of the manuscript. FJI, HJB, RN, OK and AEB commented on the protocol as far as their special skills (see Acknowledgements) are concerned. The final version of the manuscript was seen and approved by all authors.

\section{Funding}

This study is supported by unrestricted grants from Niercentrum aan de Amstel, Amstelveen, The Netherlands; and B. Braun Avitum AG, Melsungen, Germany. There will be no involvement in the collection, analysis and interpretation of data, or in the reporting of the results.

\section{Availability of data and materials}

The datasets generated and/or analyzed during the current study are not publicly available, but are available from the corresponding author on reasonable request.

\section{Declarations}

\section{Ethics approval and consent to participate}

The study will be conducted according to the principles of the WMA Declaration of Helsinki (October 2013) and in accordance with the Medical Research Involving Human Subjects Act (WMO).

Approval for the conduction of this study was obtained from the Institutional Ethics Committee of the VU University Medical Center, Amsterdam UMC, Amsterdam, The Netherlands (METC VUmc: 2017.581 / NL61210.029.17). This study is conducted according to good clinical practice (GCP) guidelines. The research doctors shall inform patients about the 
explanatory document and the consent forms are signed and dated by the subjects individually.

\section{Consent for publication}

Not Applicable.

\section{Competing interests}

PAR, MJN and MPCG report grant support from Niercentrum aan de Amstel, Elyse Klinieken, and B. Braun Avitum AG. All the other authors declared no competing interests.

\section{Received: 9 November 2020 Accepted: 1 April 2021 Published online: 15 April 2021}

\section{References}

1. Grooteman MP, van den Dorpel MA, Bots ML, Penne EL, van der Weerd NC, Mazairac $\mathrm{AH}$, et al. Effect of online hemodiafiltration on all-cause mortality and cardiovascular outcomes. J Am Soc Nephrol. 2012;23(6):1087-96. https://doi.org/10.1681/ASN.2011121140.

2. Ok E, Asci G, Toz H, Ok ES, Kircelli F, Yilmaz M, et al. Mortality and cardiovascular events in online haemodiafiltration (OL-HDF) compared with high-flux dialysis: results from the Turkish OL-HDF study. Nephrol Dial Transplant. 2013;28(1):192-202. https://doi.org/10.1093/ndt/gfs407.

3. Morena M, Jaussent A, Chalabi L, Leray-Moragues $H$, Chenine L, Debure A, et al. Treatment tolerance and patient-reported outcomes favor online hemodiafiltration compared to high-flux hemodialysis in the elderly. Kidney Int. 2017;91(6):1495-509. https://doi.org/10.1016/j.kint.2017.01.013.

4. Maduell F, Moreso F, Pons M, Ramos R, Mora-Macia J, Carreras J, et al. Highefficiency postdilution online hemodiafiltration reduces all-cause mortality in hemodialysis patients. J Am Soc Nephrol. 2013;24(3):487-97. https://doi. org/10.1681/ASN.2012080875.

5. Peters SA, Bots ML, Canaud B, Davenport A, Grooteman MP, Kircelli F, et al. Haemodiafiltration and mortality in end-stage kidney disease patients: a pooled individual participant data analysis from four randomized controlled trials. Nephrol Dial Transplant. 2016;31(6):978-84. https://doi.org/10.1093/ ndt/gfv349.

6. Nube MJ, Peters SAE, Blankestijn PJ, Canaud B, Davenport A, Grooteman MPC, et al. Mortality reduction by post-dilution online-haemodiafiltration: a cause-specific analysis. Nephrol Dial Transplant. 2017;32(3):548-55.

7. Rama ILI, Fontova P, Cerezo G, Soto C, Javierre C, Hueso M, et al. Online haemodiafiltration improves inflammatory state in dialysis patients: a longitudinal study. PLoS One. 11:e0164969.

8. Leurs $P$, Lindholm B, Stenvinkel P. Effects of hemodiafiltration on uremic inflammation. Blood Purif. 2013;35(Suppl 1):11-7. https://doi.org/10.1159/ 000346359 .

9. den Hoedt $\mathrm{CH}$, Bots ML, Grooteman MP, van der Weerd NC, Mazairac AH, Penne EL, et al. Online hemodiafiltration reduces systemic inflammation compared to low-flux hemodialysis. Kidney Int. 2014;86(2):423-32. https:// doi.org/10.1038/ki.2014.9.

10. Meyring-Wosten $\mathrm{A}$, Zhang $\mathrm{H}$, Ye $\mathrm{X}$, Fuertinger DH, Chan L, Kappel $\mathrm{F}$, et al. Intradialytic hypoxemia and clinical outcomes in patients on hemodialysis. Clin J Am Soc Nephrol. 2016;11(4):616-25. https://doi. org/10.2215/CJN.08510815.

11. Campos I, Chan L, Zhang H, Deziel S, Vaughn C, Meyring-Wosten A, et al. Intradialytic hypoxemia in chronic hemodialysis patients. Blood Purif. 2016 41(1-3):177-87. https://doi.org/10.1159/000441271

12. Locatelli F, Altieri P, Andrulli S, Bolasco P, Sau G, Pedrini LA, et al. Hemofiltration and hemodiafiltration reduce intradialytic hypotension in ESRD. J Am Soc Nephrol. 2010;21(10):1798-807. https://doi.org/10.1681/A SN.2010030280.

13. Donauer J, Schweiger C, Rumberger B, Krumme B, Bohler J. Reduction of hypotensive side effects during online-haemodiafiltration and low temperature haemodialysis. Nephrol Dial Transplant. 2003;18(8):1616-22. https://doi.org/10.1093/ndt/gfg206.

14. Wang AY, Ninomiya T, Al-Kahwa A, Perkovic V, Gallagher MP, Hawley C, et al. Effect of hemodiafiltration or hemofiltration compared with hemodialysis on mortality and cardiovascular disease in chronic kidney failure: a systematic review and meta-analysis of randomized trials. Am J Kidney Dis. 2014;63(6):968-78. https://doi.org/10.1053/j.ajkd.2014.01.435.

15. Susantitaphong $P$, Siribamrungwong $M$, Jaber BL. Convective therapies versus low-flux hemodialysis for chronic kidney failure: a meta-analysis of randomized controlled trials. Nephrol Dial Transplant. 2013;28(11):2859-74. https://doi.org/10.1093/ndt/gft396.

16. Di Filippo S, Manzoni C, Andrulli S, Tentori F, Locatelli F. Sodium removal during pre-dilution haemofiltration. Nephrol Dial Transplant. 2003;18(Suppl 7):vii31-6 discussion vii57-38.

17. Thang $\mathrm{OH}$, Serne EH, Grooteman MP, Smulders YM, ter Wee PM, Tangelder GJ, et al. Capillary rarefaction in advanced chronic kidney disease is associated with high phosphorus and bicarbonate levels. Nephrol Dial Transplant. 2011;26(11):3529-36. https://doi.org/10.1093/ndt/gfr089.

18. Kelleher SP, Robinette JB, Conger JD. Sympathetic nervous system in the loss of autoregulation in acute renal failure. Am J Phys. 1984;246(4 Pt 2): F379-86.

19. Palmer BF, Henrich WL. Recent advances in the prevention and management of intradialytic hypotension. J Am Soc Nephrol. 2008;19(1):811. https://doi.org/10.1681/ASN.2007091006.

20. Odudu A, McIntyre CW. An update on Intradialytic cardiac dysfunction. Semin Dial. 2016;29(6):435-41. https://doi.org/10.1111/sdi.12532.

21. Abe S, Yoshizawa M, Nakanishi N, Yazawa T, Yokota K, Honda M, et al. Electrocardiographic abnormalities in patients receiving hemodialysis. Am Heart J. 1996;131(6):1137-44. https://doi.org/10.1016/S0002-8703(96)90088-5.

22. Singh N, Langer A, Freeman MR, Goldstein MB. Myocardial alterations during hemodialysis: insights from new noninvasive technology. Am J Nephrol. 1994;14(3):173-81. https://doi.org/10.1159/000168710.

23. Buchanan C, Mohammed A, Cox E, Kohler K, Canaud B, Taal MW, et al Intradialytic cardiac magnetic resonance imaging to assess cardiovascular responses in a short-term trial of hemodiafiltration and hemodialysis. J Am Soc Nephrol. 2017;28(4):1269-77. https://doi.org/10.1681/ASN.2016060686.

24. Selby NM, Burton JO, Chesterton $\amalg$, Mclntyre CW. Dialysis-induced regional left ventricular dysfunction is ameliorated by cooling the dialysate. Clin J Am Soc Nephrol. 2006;1(6):1216-25. https://doi.org/10.2215/CJN.02010606.

25. Kramann R, Erpenbeck J, Schneider RK, Rohl AB, Hein M, Brandenburg VM, et al. Speckle tracking echocardiography detects uremic cardiomyopathy early and predicts cardiovascular mortality in ESRD. J Am Soc Nephrol. 2014; 25(10):2351-65. https://doi.org/10.1681/ASN.2013070734

26. Mclntyre CW, Burton JO, Selby NM, Leccisotti L, Korsheed S, Baker CS, et al. Hemodialysis-induced cardiac dysfunction is associated with an acute reduction in global and segmental myocardial blood flow. Clin J Am Soc Nephrol. 2008;3(1):19-26. https://doi.org/10.2215/CJN.03170707.

27. Dasselaar JJ, Slart RH, Knip M, Pruim J, Tio RA, Mclntyre CW, et al. Haemodialysis is associated with a pronounced fall in myocardial perfusion. Nephrol Dial Transplant. 2009;24(2):604-10.

28. Flythe JE, Xue H, Lynch KE, Curhan GC, Brunelli SM. Association of mortality risk with various definitions of intradialytic hypotension. J Am Soc Nephrol. 2015;26(3):724-34. https://doi.org/10.1681/ASN.2014020222.

29. Jakob SM, Ruokonen E, Vuolteenaho O, Lampainen E, Takala J. Splanchnic perfusion during hemodialysis: evidence for marginal tissue perfusion. Crit Care Med. 2001;29(7):1393-8. https://doi.org/10.1097/ 00003246-200107000-00015.

30. Vanholder R, Glorieux $G$. The intestine and the kidneys: a bad marriage can be hazardous. Clin Kidney J. 2015;8(2):168-79. https://doi.org/10.1 093/ckj/sfv004.

31. Carracedo J, Merino A, Nogueras S, Carretero D, Berdud I, Ramirez R, et al. On-line hemodiafiltration reduces the proinflammatory CD14+CD16+ monocyte-derived dendritic cells: a prospective, crossover study. J Am Soc Nephrol. 2006;17(8):2315-21. https://doi.org/10.1681/ASN.2006020105.

32. McIntyre CW, Harrison LE, Eldehni MT, Jefferies HJ, Szeto CC, John SG, et al. Circulating endotoxemia: a novel factor in systemic inflammation and cardiovascular disease in chronic kidney disease. Clin J Am Soc Nephrol. 2011;6(1):133-41. https://doi.org/10.2215/CJN.04610510.

33. Szeto CC, McIntyre CW, Li PK. Circulating bacterial fragments as cardiovascular risk factors in CKD. J Am Soc Nephrol. 2018;29(6):1601-8. https://doi.org/10.1681/ASN.2018010068.

34. Wang $F$, Jiang $H$, Shi $K$, Ren $Y$, Zhang $P$, Cheng $S$. Gut bacterial translocation is associated with microinflammation in end-stage renal disease patients. Nephrology (Carlton, Vic). 2012;17(8):733-8.

35. Odudu A, Eldehni MT, McCann GP, McIntyre CW. Randomized controlled trial of individualized dialysate cooling for cardiac protection in hemodialysis patients. Clin J Am Soc Nephrol. 2015;10(8):1408-17. https:// doi.org/10.2215/CJN.00200115.

36. van der Sande FM, Wystrychowski G, Kooman JP, Rosales L, Raimann J, Kotanko $P$, et al. Control of core temperature and blood pressure stability 
during hemodialysis. Clin J Am Soc Nephrol. 2009;4(1):93-8. https://doi. org/10.2215/CJN.01800408.

37. Mustafa RA, Bdair F, Akl EA, Garg AX, Thiessen-Philbrook H, Salameh $H$, et al. Effect of lowering the dialysate temperature in chronic hemodialysis: a systematic review and meta-analysis. Clin J Am Soc Nephrol. 2016;11(3):44257. https://doi.org/10.2215/CJN.04580415.

38. Maggiore Q, Pizzarelli F, Dattolo P, Maggiore U, Cerrai T. Cardiovascular stability during haemodialysis, haemofiltration and haemodiafiltration. Nephrol Dial Transplant. 2000;15(Suppl 1):68-73. https://doi.org/10.1093/ oxfordjournals.ndt.a027967.

39. Maggiore Q, Pizzarelli F, Santoro A, Panzetta G, Bonforte G, Hannedouche T, et al. The effects of control of thermal balance on vascular stability in hemodialysis patients: results of the European randomized clinical trial. Am J Kidney Dis. 2002;40(2):280-90. https://doi.org/10.1053/ajkd.2002.34506.

40. Maggiore Q, Pizzarelli F, Sisca S, Zoccali C, Parlongo S, Nicolò F, et al. Blood temperature and vascular stability during hemodialysis and hemofiltration. Trans Am Soc Artif Intern Organs. 1982;28:523-7.

41. Maggiore Q, Pizzarelli F, Zoccali C, Sisca S, Nicolò F, Parlongo S. Effect of extracorporeal blood cooling on dialytic arterial hypotension. Proc Eur Dial Transplant Assoc. 1981;18:597-602.

42. Levin NW, Morris AT, Lavarias VA, Wang Y, Glabman MB, Leung JP, et al. Effects of body core temperature reduction on haemodynamic stability and haemodialysis efficacy at constant ultrafiltration. Nephrol Dial Transplant. 1996;11(Suppl 2):31-4. https://doi.org/10.1093/ndt/11.supp2.31.

43. Schneditz D, Martin K, Krämer M, Kenner T, Skrabal F. Effect of controlled extracorporeal blood cooling on ultrafiltration-induced blood volume changes during hemodialysis. J Am Soc Nephrol. 1997;8(6):956-64.

44. Kaufman AM, Morris AT, Lavarias VA, Wang Y, Leung JF, Glabman MB, et al. Effects of controlled blood cooling on hemodynamic stability and urea kinetics during high-efficiency hemodialysis. J Am Soc Nephrol. 1998;9(5): 877-83.

45. Daugirdas JT. Lower cardiovascular mortality with high-volume hemodiafiltration: a cool effect? Nephrol Dial Transplant. 2016;31(6):853-6. https://doi.org/10.1093/ndt/gfv412.

46. Randomization.com. 2017. http://www.randomization.com. Accessed 2 Oct 2020.

47. Dutch Federation of Nephrology (NFN). 2020. https:/www.nefro.nl/ richtlijnen. Accessed 28 Oct 2020

48. KDOQI clinical practice guideline for hemodialysis adequacy: 2015 update. Am J Kidney Dis 2015, 66(5):884-930.

49. de Roij van Zuijdewijn CLM, Chapdelaine I, Nubé MJ, Blankestijn PJ, Bots ML, Konings $C$, et al. Achieving high convection volumes in postdilution online hemodiafiltration: a prospective multicenter study. Clin Kidney J. 2017;10(6): 804-12. https://doi.org/10.1093/ckj/sfw140.

50. Uhlin F, Fridolin I, Lindberg LG, Magnusson M. Estimation of delivered dialysis dose by on-line monitoring of the ultraviolet absorbance in the spent dialysate. Am J Kidney Dis. 2003;41(5):1026-36. https://doi.org/10.101 6/S0272-6386(03)00200-2.

51. Jhamb M, Tamura MK, Gassman J, Garg AX, Lindsay RM, Suri RS, et al. Design and rationale of health-related quality of life and patient-reported outcomes assessment in the frequent hemodialysis network trials. Blood Purif. 2011;31(1-3):151-8. https://doi.org/10.1159/000321855.

52. Lindsay RM, Heidenheim PA, Nesrallah G, Garg AX, Suri R. Minutes to recovery after a hemodialysis session: a simple health-related quality of life question that is reliable, valid, and sensitive to change. Clin J Am Soc Nephrol. 2006;1(5):952-9. https://doi.org/10.2215/CJN.00040106.

53. Rayner HC, Zepel L, Fuller DS, Morgenstern H, Karaboyas A, Culleton $\mathrm{BF}$, et al. Recovery time, quality of life, and mortality in hemodialysis patients: the Dialysis Outcomes and Practice Patterns Study (DOPPS). Am J Kidney Dis. 2014;64(1):86-94. https://doi.org/10.1053/j.j.jkd.2014. 01.014 .

54. Regier T, Kay P. Language, thought, and color: Whorf was half right. Trends Cogn Sci. 2009;13(10):439-46. https://doi.org/10.1016/j.tics.2009.07.001.

55. Kandel ERSJ, Jessell TH, Siegelbaum SA, Hudspeth AJ, Mack S. Principles of neural science. 5th ed. New York: McGraw-Hill Companies, Inc.; 2013.

56. Penáz J, Voigt A, Teichmann W. Contribution to the continuous indirect blood pressure measurement. Z Gesamte Inn Med. 1976;31(24):1030-3.

57. Budding AE, Grasman ME, Lin F, Bogaards JA, Soeltan-Kaersenhout DJ, Vandenbroucke-Grauls CMJE, et al. IS-pro: high-throughput molecular fingerprinting of the intestinal microbiota. FASEB J. 2010;24(11):4556-64. https://doi.org/10.1096/fj.10-156190.
58. Budding AE, Hoogewerf M, Vandenbroucke-Grauls CM, Savelkoul PH. Automated broad-range molecular detection of bacteria in clinical samples. J Clin Microbiol. 2016;54(4):934-43. https://doi.org/10.1128/JCM.02886-15.

59. van der Pol E, Coumans FA, Grootemaat AE, Gardiner C, Sargent IL, Harrison $P$, et al. Particle size distribution of exosomes and microvesicles determined by transmission electron microscopy, flow cytometry, nanoparticle tracking analysis, and resistive pulse sensing. J Thromb Haemost. 2014;12(7):1182-92. https://doi.org/10.1111/jth.12602.

60. Bonten TN, Siegerink B, van der Bom JG. Cross-over studies. Ned Tijdschr Geneeskd. 2013;157(3):A5542.

61. https://www.castoredc.com/. Accessed 28 Oct 2020.

\section{Publisher's Note}

Springer Nature remains neutral with regard to jurisdictional claims in published maps and institutional affiliations.
Ready to submit your research? Choose BMC and benefit from:

- fast, convenient online submission

- thorough peer review by experienced researchers in your field

- rapid publication on acceptance

- support for research data, including large and complex data types

- gold Open Access which fosters wider collaboration and increased citations

- maximum visibility for your research: over $100 \mathrm{M}$ website views per year

At BMC, research is always in progress.

Learn more biomedcentral.com/submissions 